\title{
Kant's Conception of a Causality through Freedom
}

\author{
BRENT A. SINGER \\ University of Colorado, Boulder
}

$\mathbf{I}$

This paper examines the meaning and justification which Kant gives to his concept of human freedom. I begin with the deduction of freedom in the second Critique. This deduction of freedom from the moral law appears "unexpectedly" in a section ostensibly devoted to the deduction of that same moral law, a deduction which, it turns out, is both unneeded and out of reach (47). 1 Further inquiry directs us to the antinomies of pure reason in the transcendental dialectic of the first critique. Combining the results obtained from these two sources, I summarize and briefly criticize Kant's arguments for the validity of his concept of causation through freedom.

Kant asserts that the moral principle serves as a principle of the deduction of the faculty of freedom (47). The principle to which he is referring is what he also calls the fundamental law of pure practical reason, or, more briefly, the moral law: "So act that the maxim of your will could always hold at the same time as a principle establishing universal law" (31).

With regard to this principle, Kant says that it needs no further justification, which is to say, it stands in need of no deduction. This contrasts sharply with the categories and principles of the understanding whose objective and universal validity with respect to appearances required and received justification in the transcendental deduction of the first Critique. This deduction showed how a non-empirical synthesis could possess truth by its agreement with the conditions without which objective experience would not be possible. The success of this deduction depended upon reference to objects of possible experience, which is to say, reference to the possibility of such objects. But lacking any reference to the possibility of experience, the objective reality of the moral law cannot be deduced in the manner of the first Critique (47). Indeed, says Kant, it cannot be deduced at all (47). 
Nevertheless, the moral law is firmly established of itself (47). According to Kant, the moral law is an entirely a priori and apodictically certain fact of pure reason (47). Moreover, the moral law serves as a principle of the deduction of freedom as a causality of pure reason because it both is a definite law of causality through freedom, and it defines the law of causality through freedom (47). The moral law thereby gives objective reality, practically speaking, to the concept of a causality through freedom (48). In addition, by analogy, the moral law is a law of the possibility of a supersensuous nature, just as the principle of the analogies of experience is a law of the possibility of a sensuous nature (48).

For Kant, this is tantamount to the claim that the moral law gives a positive definition to the concept of freedom as a causality of pure reason. This positive definition is that of "a reason which determines the will directly through the condition of a universal lawful form of the maxim of the will" (48). It.is significant that this is a positive definition because theoretical reason, which takes freedom as fulfilling one of its own needs, can nonetheless only think a causality through freedom negatively.

The deduction of freedom from the moral law is therefore based upon the following: (1) the moral law is a law of causality through freedom; (2) the moral law defines the law of causality through freedom; the moral law is the law of the possibility of a supersensuous nature; (4) the moral law is an a priori. apodictic fact of pure reason; and (5). theoretical reason requires the idea of freedom, but can only think it as a bare possibility, negatively, yet without contradiction. An examination of the antinomies of pure reason will help to clarify this fifth condition.

\section{I I}

Kant identifies in man a desire to trace back a given condition to its unconditioned source. The inevitable result is transcendental illusion, the endeavor to extend the application of pure understanding beyond the limits of possible experience (B352). This desire is inseparable from human reason whose principle in its logical employment is "to find for the conditioned knowledge obtained through the understanding the unconditioned whereby its unity is brought to completion" (B364). This principle does not prescribe any law for objects, but rather expresses a subjective necessity for the orderly advancement of our knowledge of nature. This subjective determination of thought becomes a principle of pure reason on the presupposition that if the conditioned is given, the whole series of conditions (a series which is itself unconditioned) is also given (B364). 
Concepts of pure reason, for Kant, are called "transcendental ideas" (B368). These ideas can never be derived from sensory experience, but are rather products of reason itself. Concepts of pure reason are concepts of totality in the synthesis of conditions, a totality made possible by the unconditioned. For example, "the absolute whole of all appearances" is a transcendental idea. No object adequate to it can ever be given through human intuition, which is to say, given according to the forms of space and time.

Thus in one sense such ideas are "merely ideas." But even if ideas of the unconditioned can never determine an object of experience so that by this we acquire knowledge of nature, such ideas nevertheless perform vital functions for the employment of both theoretical and practical reason. For the former, ideas of the unconditioned regulate our search for empirical knowledge by representing to us a totality as an ideal to strive toward, which is to say, such ideas become components in regulative principles. For the latter, the idea of the unconditioned is indispensable because all consciousness of obligation proceeds under the idea of the unconditioned (B383).

According to Kant, when pure reason ascends to the idea of the unconditioned via hypothetical syllogisms. it arrives at the transcendental concept of the absolute completeness of the series of conditions for a given appearance. This transcendental concept of reason becomes the subject matter for a purported transcendental science of the world, a so-called "pure rational cosmology" (B435). The outcome of this "cosmology," however, is four antinomies into which reason unavoidably falis. Each antinomy corresponds to one of four cosmological ideas that are generated by reason's ascent to the unconditioned according to appropriate concepts of pure understanding. The unconditioned, which is the basis of each cosmological idea, can be conceived as a special member of the series of conditions, a member which is itself unconditioned. This member is called the first of the series. The four cosmological ideas generated by a transcendental science of the world are thus "the beginning of the world," "the simple in respect to the parts of a whole," "freedom in respect to causes," and "absolute necessity in respect to the existence of alterable things" (B446).

These ideas are antithetical in transcendental cosmology because for each of them reason presents arguments that there both is and is not such a thing. For example, the third antinomy asserts that there is a causality through freedom, and that there is not. Furthermore, it presents arguments as well and equaliy grounded on both sides. This state of affairs, according to Kant, threatens the very integrity of philoso- 
phy, which assumes reason's thoroughgoing consistency and ultimate unity.

The dilemma facing reason is thus the following: on the one hand, reason has a stake in demonstrating the truth of the thesis that there is freedom (or at least, the falsity of the antithesis). This is because, according to Kant, (1) morality necessarily presupposes a causality through freedom as a property of our will (Bxxix) and (2) the antithesis that there is no such first member of the series of conditions generally renders the completion of the edifice of our speculative knowledge guite impossible by holding that an unconditioned is nowhere discernible. And this latter, for Kant, amounts to denying the pure a priori unity of reason itself (B503).

On the other hand, even though reason has this stake in demonstrating the truth of the thesis that there is a causality through freedom, reason cannot rest with a dialectical proof of it, a proof which, in particular, rests upon the same grounds as its antithesis. Thus the higher task of reason in the first Critique is to fulfill its own needs by revealing the dialectical nature of the arguments which establish equally the thesis and antithesis while at the same time leaving open the possibility that there is a causality through freedom. Kant believed that the genius of his transcendental idealism, as well as one aspect of its confirmation, is that when the antinomies are lcoked at from the standpoint of transcendental idealism, just these results that are demanded by the higher task of reason are those results which obtain. Our task is therefore to see upon what illusory grounds the antinomies stand, and to see how transcendental idealism allows for the possibility of freedom.

According to Kant, both the thesis and the antithesis of each antinomy rest upon the following dialectical inference:

(1) If the conditioned is given, the entire series of all its conditions is likewise given.

(2) Appearances are given as conditioned.

(3) Therefore, if the conditioned appearance is given, ali its conditions (as appearances) are likewise given.

This is a dialectical inference because of an ambiguity in the word 'conditioned'. In (1), the conditioned is thought as a thing in itself, and not in terms of whether or how we can know it. In this case, the entire series of all its conditions is necessarily given with the condition as its very possibility. But in (2). the conditioned is not taken as a thing in itself. but as an appearance. In this case it is only by means of, and within, a successive (temporal) synthesis that the members of the series of the conditioned could be 
given. Thus here one can no longer assume that the totality of the synthesis of conditions is given, or ever could be given, as completed. This means that what is merely an appearance is taken logically as if it had properties which can only be thought as belonging to things in themselves.

We can see this sort of dialectical inference at work in the third antinomy by considering two pairs of propositions:

(1a) The series of antecedent causes in nature is infinite (i.e., there is no first member of this series in nature).

(1b) The series of antecedent causes in nature is not infinite.

(2a) The series of antecedent causes in nature is infinite.

(2b) The series of antecedent causes in nature is finite.

The point to see is that the third antinomy fails to distinguish (1b) from (2b) because it fails to observe the difference between appearances and things in themselves. The third antinomy treats (2a) and (2b) as contradictory propositions, so that each must have a different truth value. This presupposes that the series of causes in nature is a thing in itself by thinking it according to the idea of an absolute totality. That is, to hold that (2a) and (2b) are contradictories is to hold that a series given in nature can be given as a totality in which the regress required to determine this series is absolutely complete. But nature, in which the series is given, is not given as a thing in itself, and so it is never given as an unconditioned whole, and likewise with any series of conditions within it. Thus neither (2a) nor (2b) is true because no object in nature can ever be given that is adequate to either one. Only (1b) is correctly stated in that it does not treat nature as something in itself, but only affirms that one cannot determine whether or not a series of conditions in nature is itself determined by an unconditioned first member.

Having shown the dialectical basis for the thesis and antithesis, Kant then explains how the distinction between appearance and thing in itself (how transcendental idealism) allows for the possibility of freedom in a fuller sense than the mere recognition that there is a fallacy involved in the assertion of the antithesis that there is no such freedom. This explanation equates things in themselves with what is intelligible, so that the intelligible becomes whatever it is in an appearance which is not itself an appearance, but is still a ground for that appearance. Kant writes: 
If, therefore, that which in the sensible world must be regarded as appearance has in itself a faculty which is not an object of sensible intuition, but through which it can be the cause of appearances, the causality of this being can be regarded from two points of view. Regarded as the causality of a thing in itself, it is intelligible in its action; regarded as the causality of an appearance in the world of sense, it is sensible in its effects. We should therefore.have to form both an empirical and an intellectual concept of the causality of the faculty of such a subject, and to regard both as referring to one and the same effect. (B567, emphasis added)

In other words, Kant has us think an intelligible character which is a ground for actions which are appearances, but this intelligible character could never itself be an appearance. Such a character is not temporally or spatially determined, and we can never have knowledge based on intuitions that there is such a character. But since the principle of causality. through nature only applies to things as appearances. one can always, without contradiction, think the object not as sensible appearance, but in its intelligible character, and thereby think the object as under the law of freedom. It is useless to ask further how a cause that never appears can yet be the "cause" of appearances if by this question one demands an answer in terms of knowledge based upon the schematism of the concepts of the understanding. No such knowledge as this is ever in the least bit possible. What is possible, however, is to think freedom according to the terms of transcendental idealism. By so doing we encounter no contradictions with what must otherwise hold good for all experience. Thus reason fulfills its higher task by revealing the dialectical nature of the antinomies of pure reason while at the same time leaving open the possibility of a causality through freedom.

\section{IV}

We can now summarize these findings by reviewing three answers to the general question, "For Kant, why is it valid to think in terms of a causality through

First, the assertion that there is only a causality through nature has been shown to be fallacious, and a causality through freedom can be thought without contradiction. This by itself provides no positive ground to think in terms of freedom, but it does at least leave open the possibility. Note, however, that Kant's 
analysis at this point rests entirely on his transcendental idealism.

Second, the moral law is an apodictically certain fact of pure reason, and in turn, the moral law is a principle in the deduction of freedom. This means, once again, that the moral law gives a positive definition to a causality through freedom. Kant explaing this by saying that "though freedom is the ratio essendi of the moral law, the moral law is the ratio cognoscendi of freedom" (5n). We become acquainted with freedom through the moral law, but were there no freedom, there would be no moral law. At the risk of a misleading analogy, one could imagine a case in which one would not have known about a fire unless he saw the smoke, and yet, without the fire, there would have been no smoke. The most serious drawback to this analogy is of course that smoke and fire are empirically given and related through natural causation. And although not exactly identical, the moral law and freedom are more intimately united than smoke and fire. For as we have seen, the moral law is a law of freedom, it defines that law, and it is unconditional, whereas the smoke from a fire is conditioned by many factors in addition to the fire. ${ }^{2}$

Certainly there is something at least peculiar about this seemingly circular doctrine of the mutual intelligibility and virtual identity of freedom and the moral law. But regardless of the exact nature of this relation, it is fairly obvious that whatever else this doctrine might be, it is simply part of Kant's more technically developed formulation of his original thesis that morality presupposes a causality through freedom as a property of our will (Bxxix). And it is this latter that I take to be the third and most basic answer to our question. Some critical remarks at this point may at least help to clarify what issues are at stake.

What bothers many about Kant's doctrine of two causalities is a sense that it is an awkward dualism designed to save the day for morality in the face of a radical mechanistic materialism. The fact that apparently we can never hope to understand how the noumenal and phenomenal are "put together" any more than we can hope to understand how Descartes' thinking substance can affect bodies makes Kant's dualism seem mysterious and absurd: a shaky foundation at best for an ethical system. This line of thought, however, leads us astray--or at least, I shall offer some remarks on behalf of Kant on this point.

Ontologically Descartes was at least a dualist (depending on what one does with God). But what about Kant? One view is that Kant gave up ontology for epistemology, and this is to some extent true. But one must be careful not to overlook Kant's ontology, and moreover, not to put his ontology where his episte- 
mology belongs. It sometimes sounds as if Kant is ontologically a dualist with respect to the noumenal and phenomenal. But, I shall argue, this is epistemology and not ontology. To understand this is to understand why there is really no question as to the link between these "two worlds."

The concept of causality through nature is valid in the descriptions of the world given by natural scientists. In this regard the concept has objective validity, and the objects in these descriptions are temporally and spatially determined. The concept of causality that is valid in practical reflection, however, is not the same concept. Rather, the concept of causation that is appropriate in practical reflection is the concept of causation through freedom. Such a concept has no objective validity with regard to objects in space and time. Nonetheless it is a manifest aspect of first person experience as singular beings acting in the world. Such experience by itself, however, does not entail ontological dualism. That we as moral agents can adopt the viewpoint of freedom is no evidence for what there is. In fact, as Kant himself puts it, though there may be two viewpoints, there is only one effect (B567); in this regard, ontologically, Kant is a monist.

Thus insofar as Kant's claim that morality necessarily presupposes a causality through freedom is taken as an ontological claim about the separation of a free will from nature, his claim appears weak and mysterious. But insofar as one is careful to separate the two viewpoints involved by which one arrives at the idea of freedom and the concept of natural causation, then the very question of "How does the free will affect things in space and time?" loses its meaning.

\section{NOTES}

'All references without the letter ' $B$ ' as the first digit are to the pages of the Prussian Academy edition, Volume $V$, as they appear in the running-heads of Kant's Critique of Practical Reason, translated by Lewis White Beck (Indianapolis: Bobbs-Merrill Company, Inc., 1956). All references with the letter ' $B$ ' as the first digit are to the pages of the second edition (1787) of Kant's Critique of Pure Reason, translated by Norman Kemp Smith (New York: st. Martin's Press, 1965).

${ }^{2}$ At one point Kant goes so far as to say that consciousness of the moral law and consciousness of freedom amount to the same thing (46). 


\title{
Quality, Genus, and Law as Forms of Thinking
}

\author{
ODED BALABAN
}

University of Haifa, Israel

The process of substance becoming subject is the most highly speculative issue in Hegelian philosophy. In this paper it is my intention to show that this notion is connected with the process of reality (Wirklichkeit) becoming reason (Vernünftigkeit).2 In order to account for the ideas of the "real as rational" and "substance as subject," I examine the process by which these assume their full meaning and content. Historically, this process unfolds in four stages, each of which is characterized by a distinct mode or way of thinking: (1) thinking by means of gualities, where the qualities operate as universals (mythical thinking): (2) thinking by means of genus and species (Aristotelian thinking): (3) thinking by means of laws (modern scientific thinking); and finally (4) thinking by means of universals that create their species, whereby substance becomes subject.

In Hegel's philosophy, the statement "the real is rational" 2 should not be taken to mean that there is a total identity between the two terms, as in Leibniz's principle of identity (A is A). ${ }^{3}$ Rather, the identity is between different terms ( $A$ is $B$ ). An identity is achieved here precisely because there is a qualitative difference between reality and rationality. This identity must be understood in the context of knowledge in which there is a distinction between what I call the form and the content of knowledge. In this context. reality is conceived of as the content of reason, and reason as the form of reality. In other words, reality (content) may be known in different ways and by means of a variety of categories that are determined by knowledge and not by reality. Although these categories refer to one and the same reality, there are different modes of apprehending it on the basis of criteria that pertain to the process of knowledge alone, as distinct from the process of reality--i.e. of the known object. Nevertheless, this difference is ultimately resolved into a unity that is treated as Absolute Idea by Hegel in The Science of Logic, and as Absolute Science in The Phenomenology of Spirit." 
The form of knowledge may be defined as the way in which the subject comes to know the object. This is not a psychological category, but an epistemological one. The distinction between the form of knowledge and its content (the "object," in Hegel's nomenclature) is that between the what and the how of knowledge. It is a distinction between the process of knowing and the thing known.

Moreover, according to Hegel, the form of knowledge is different from the object or the content of knowledge. It is a reality in its own right, and therefore the process of knowing per se is neither true nor false, but has an ontological existence of its own. Hegel calls this form of knowledge "concept," and he terms the object or content of knowledge "substance." For Hegel, the concept is not substance but "the truth of substance" (Science 577), and can therefore be treated as different from its content or substance. That is to say, it can be an object of knowledge. In this capacity it has a history of its own. The aim of this paper is to trace the outlines of the conception of the historical development of the form of knowledge as presupposed in Hegel's theory of Judgement. However, before this issue can properly be dealt with, we need first to consider the relationship between the individual and the universal.

The relationship between the individual (Das Einzeine) and the universal (Das Allgemeine) pertains purely to the sphere of the form of knowledge. Hegel discusses this relationship in the thira part of The Science of Logic, when dealing with judgement and syllogism. According to Hegel, a judgement is essentially a "primal division" (Ur-teil) of the individual and the universal (Science 625). It is a unity whose nature is to split up into correlative opposite elements which are the subject and the predicate. These function as opposites of one another in the sense that if the subject denotes something individual or particular, then the predicate functions as a universal that is relative to the subject. Thus, in its formal aspect, every judgement states that the individual is universal and the universal is individual. Therefore the nature of the individual is determined by that of the universal, and the universal attains concreteness in the individual.

Moreover, every judgement states that the subject "is" the predicate. The division of the subject and the predicate coincides with that of the known and the unknown, so that in a typical judgement the subject is the unknown aspect of the judgement, and the predicate is the known aspect: the subject is the explanandum and the predicate the explanans. 
This attribution of a predicate to a subject is the way in which concepts are created. Moreover, for Hegel, the concept is identical with judgement. Indeed it would be false to argue that two concepts are brought together in a judgement--that there is a subject-concept on one hand, and a predicate-concept on the other. Rather, these two join to form the concept. A concept is by its very nature something that has to be explained. And if the subject-concept has already been explained before it is related to the predicate, there is clearly no need for the predicate. Further, if the subject-concept is even partially known, then it is precisely the partially known aspect of the subject that is irrelevant to any judgement. A judgement is enunciated for the very reason that the concept was not understood. In other words, the explanandum is not yet a concept and therefore requires being explained-requires that a concept of it should be formed. Thus concept and judgement are the same thing, but expressed in different ways: a concept is an abstraction derived from its components, the subject and the predicate; a judgement is the concept made concrete-it is the inner structure of the concept. So long as a concept does not assume a judgemental guise and remains abstract, its structure is incomplete. Completion takes place when the concept becomes concrete as judgement.

Therefore, a meaningful concept can only be one which has previously functioned as subject in a judgement. It is in this way that a concept becomes meaningful. Hence a concept can fulfill an explanatory function only if it has already functioned as a term requiring explanation and has been explained. Only that which needs to be explained can form a judgement. To illustrate let us consider the following two sentences:

(i) Socrates is a man.

(ii) Socrates is $x$.

Now let us assume that the speaker and the listener both know that Socrates is a man, but that neither know the meaning of ' $x$ '. Given these conditions, the two sentences are not judgements. The first is not a judgement because what it claims was known before the assertion that a certain subject (Socrates) is the predicate (is a man). That is to say, by asserting the judgement the speaker has added no new information to what was already known to the listener. In Hegel's view such sentences are not judgements because they fail to offer an opposition of the known and unknown (cf. Science 624). The sentence is in fact a tautology, for all that it says is that socrates is socrates. The second sentence is not a judgement either, but for another reason. The term $x$, which acts as predicated, is itself in need of interpretation, and one cannot ex- 
plain something by means of that which is itself in 'need of being explained.5

But why should the difference between the explanans (predicate) and the explanandum (subject) be formulated as a contrast between known and unknown? The answer is that the relevance of the difference to the meaning of the sentence resides. in the very opposition between the known and unknown aspects; for that which demands an explanation does so in regard to the aspect of itself which is unknown. It is precisely the unknown aspect of a sentence which is relevant to judgement, and which leads to the assertion of the judgement; the unknown aspect is totally unknown. The predicate (the explanans) acts as a predicate even if unknown aspects are included within it. These unknown aspects of the predicate, however, are irrelevant to the judgement. Only the known aspect of the predicate is relevant. It follows, therefore, that it is the opposition of the known and unknown and not merely the difference between them which characterizes the judgement.

Thus there is a tautological cancelling out of the known-unknown opposition in both sentences: in the first sentence the opposition is annulled by the tautology of the known, for Socrates is no less known than is his state of being a man; and in the second by the tautology of the unknown, for Socrates is no less unknown than $x$. The same may be said of the opposition of the individual and universal. In the first sentence, Socrates does not function as an individual in contrast to the universal 'a man', for the idea of Socrates includes in itself the universal idea of his being a man because we already know beforehand. that Socrates means 'a man', so that the predicate adds nothing to our understanding of the known aspect of the subject and is therefore irrelevant. The second sentence contains no individual-universal opposition, for what functions as a predicate in this sentence is a mere sign that is neither individual nor universal; hence the subject, too, functions neither as an individual nor as a universal in relation to the predicate. Neither the individual (the subject) nor the universal (the predicate) in themselves constitute concepts, but are only the constituents of concepts. Neither can be considered independently of its relationship to the other: the first is expressed in the second. Neither can be defined or grasped without reference to the other. The individual is individual only within the context of a universality. Something unknown is unknown only in reference to something that is already known. And, of course, a subject is a subject only in reference to a predicate.

Therefore a concept must be understood as a process--as a "conceptualization." It is a shuttling from subject to predicate and back again. However, this is not a symmetrical relationship; meaning is bestowed 
upon the subject by the predicate, but the predicate does not receive its meaning from the subject. The meaning of the predicate is determined by a previous judgement in which this predicate functioned as a subject. And once the predicate is stated, our consciousness returns to the subject in order to understand it. However when we go from the subject to the predicate we do not do so in order to understand the predicate but in order to return to the subject." Therefore we can say that concept is judgement; or that judgement is the most concrete expression of the concept--it is the crystallization of the concept.

on the other hand, according to Hegel judgement cannot be explained merely on the basis of the opposition between subject and predicate. Judgement is also an identity of the opposites. Thus after asserting that subject and predicate are different entities, Hegel adds that "the predicate which is attached to the subject should, however, also belong to it, that is, be in and for itself identical with it" (Science 626). The concreteness of judgement consists in its essential tendency to reconcile opposites--to relate the individual and the universal by establishing the congruence between the subject and the predicate. Moreover in the absence of such an identity, the very opposition of the known and unknown aspects would be incomprehensible and inexplicable. In order for a sentence to have meaning and be understood, the opposition of its known and unknown aspects must be preserved even while they are being identified. The subject is at one and the same time in opposition to and identical with the predicate. On the other hand, the function of the predicate is to relate to the subject. Without this mutual tending towards one another of the subject and predicate, no judgement can be asserted; nor can a judgement be asserted if the identity has already been established beforehand. In other words, judgement is to be understood only as a process and not as a final product.?

II. The Question of Meaning and the Problem of Illustration

A discussion of the illustration of judgements and the question of meaning may help to clarify Hegel's approach.

A single judgement, taken in isolation from its context, cannot be meaningful. It assumes meaning only in connection with the context in which it is asserted. That context is first of all the question or questions to which the judgement is a reply. The meaning of a judgement resides in its being an answer to a question; that is to say, its meaning comes as a result of its being connected with other judgements.

The meaning of a judgement results, as well, from the understanding of alternative answers that have been 
eliminated as a consequence of the answer furnished by the judgement itself. Thus the meaning of a judgement does not depend only upon its particular assertion but upon what was said in other relevant judgements, and even upon what is implicit though unstated. So, for example, to say that one is reading implies that one is not writing. There may even be contextual situations in which the unspoken or implicit meaning is more important than the explicit meaning. This contextual approach to meaning is characteristic of Hegel's philosophy in general.

The relevance of context to judgement has to do with the general nature of concept, since every explicitly stated concept is, at a deeper level, mediated by other concepts not explicitly stated. This is the reason that Hegel regards judgement to be syllogism (Science 664): Syllogism is obtained by making explic$i$ the mediation that implicitly operates in judgement. Generally speaking therefore, concepts, being judgements that are actually syllogisms, have accumulative character. They collect and store up content by way of functioning as subjects in judgements, thereby accumulating the predicates attributed to them. So, words and concepts are essentially different from one another. A word is merely a carrier of meaning, whereas the meaning is the concept (i.e. the accumulated meaning) carried by the word.

In attempting to understand Hegel's approach, it would be illuminating to consider his discussion of the examples used in illustrating judgement (Science 6267). Sentences like "Socrates is a man" or "Ail men are mortal" are commonly used in exemplifying judgements. In examples of this sort, both the subject and the predicate are known to us beforehand, and this is done so that we should not be distracted by their content but concentrate solely on their logical form. That form is usually expressed in the abstract as "A is $B, "$ but Hegel regards this to be wrong, since it treats the form as being completely separate from content, and this form is therefore not the form of the content. Indeed it is an empty form and, being empty, can hardly be said to qualify as a form at all. What is stated in the predicate of such sentences is already included in the subject, so that they are examples not of judgement but of tautology, wherein the predicate repeats in apparently different terms a concept already expressed by the subject. But the difference of terms between subject and predicate is not a real difference, since both of the terms, as well as the connection between them, were known beforehand. Hence, in attempting to isolate the form of judgement, we lose the very principle of judgement; that is to say, we annul the opposition of the individual and universal." For Hegel, on the other hand,. form must not be totally separated from content, for it is the way in which content is expressed. It 
therefore follows that it is impossible to exemplify judgement without taking content into account. However the accepted mode of illustrating judgements is to avoid an assertion of content, so that the instances conventionally offered in traditional logic as examples of judgement would never be asserted in any other context. In Hegel's view these are not judgements at all but mere strings of words or sounds, or what he calls "sentences" (Satze).

\section{I. Judgements and Sentences}

According to Hegel, then, a judgement is meaningful whereas a sentence is not (cf. Science 626). A sentence is merely a group of words that are grammatically connected but without meaning. A sentence can, however, become a judgement if it appears in a context that bestows meaning upon it. If a group of words like "The wind is an elephant" were to appear in an essay on the theory of relativity, it would only be a sentence and not a judgement. However the same assertion becomes a judgement in a literary or mythical context.

Another example in kind proposed by Hegel is, "Aristotle died at the age of 73 in the fourth year of the 115th olympiad" (Science 626). According to Hegel, this too is a sentence and not a judgement. It would only, be a judgement if either the date of the philosopher's death or his age at the time had been in doubt, and was confirmed by being paired with the second item of information. Only then would the data contained in the assertion have any meaning. 10

A similar argument is put forward by Hegel concerning the example. "My friend $N$. has died" (Science 626). Hegel unhesitatingly asserts that this is not a judges ment but merely a sentence; and it bears repeating that a sentence is a vacuous tautology which is without meaning. The preceding sentence "would be a judgement only if there were a question whether he [my friend N.] was really dead or only in a state of catalepsy" (Science 626). This question does not however arise in this particular context, since Hegel is clearly not about to tell us about his thoughts concerning a dead friend in a book dealing with logic. 11

For any content to be the subject of a judgement, it must function as an unknown aspect in opposition to a predicate that functions as a known aspect; moreover this unknown aspect must function as an individual in opposition to a predicate that functions as a universal. In the absence of this opposition of known and unknown, individual and universal, subject and predicate; judgement degenerates into mere tautology. Thus the date of Aristotle's death in the example cited above has no significance apart from the subject. It does not function as a universal in relation to an individual. Like the subject, the predicate is also un- 
known and therefore individual. But if what is being asserted about the individual is itself also individual, then we are dealing with a tautology--that is, with a sentence. An individual cannot be defined by means of another individual, for individuals cannot include individuals. Only when something is in doubt, or in question, does a sentence assume significance and become a judgement. 12

\section{Hegel's Attitude on the Nominalist-Realist Dispute}

The controversy between the nominalists and realists over the question of the Universal was about the ontological status of universals. Nominalists contended that beyond individuals there existed only names, whereas realists regarded universals to be real as well. Hegel treated the issue of universals from a very different point of view. The problem for him was not the ontological status but the nature of the universal. That is to say, he was concerned with how and in what sense universals define the individual. Accordingly, he proposed that there were different kinds of universals, each representing a different approach to the individual. The universal is by its very nature defined by its relation to the individual and cannot be considered separately from it. And the same may be said of the individual. If, then, the universal is defined by the individual, its nature can be discovered by way of a consideration of the individual.

To be individual means first of all to be separate and different from other individuals. Now the sole means by which this difference that distinguishes individuals may be determined is the predicate or the universal. 2 It is the universal that bestows individuality upon the individual. The individual is therefore defined and determined by universals. The greater the number of universals that are attributed to an individual, the more individuated does it become. Thus the individual, as it were, is the point at which universal coordinates converge. Moreover, since the individual is defined by universals, its individuality does not contradict its being dependent upon universals; indeed it is in this way that its individuality is established. The very definition of the individual as being related in an essential way to universals prevents it from being treated as something utterly unique and isolated.

For this reason the conventional definition of the judgement as a relationship between concepts is inappropriate to judgement. For this would suggest that the copula is an extrinsic conjunction between two concepts; when in fact the copula signifies precisely that the subject is the predicate. And if the subject is defined as subject only in the predicate, then accord- 
ing to Hegel, "it is subject only in it" (i.e., subject by virtue of the predicate; Science 625-6).

The foregoing applies to universals as well. To be universal means to be particularized into individuals. 1. Since the individual is defined by means of the universal, and the only function of the universal is to define individuals, the more the universal specifies individuals the more it becomes a "concrete universal"--that is to say, it increasingly becomes a principle of individuation. The individuals are defined by the universal in accordance with the nature of the last.

Therefore to summarize, there are no universals that are separate from individuals, and no individuals independent of universals. Since both nominalists and realists assume the independence of universals and individuals, they have both failed to grasp the nature of the universal.

\section{Ways of Thinking}

As I have already observed, Hegel's question is how and in what sense the universal defines the individual, and he addresses himself to this issue by proposing distinct kinds of universals, each of which approaches the individual in a different way.

Hegel begins his systematic discussion of these different ways of thinking with an analysis of the most abstract kinds of universal, whose connection with the individual is highly tenuous. He ends his analysis with a consideration of a concrete universal, whose concreteness depends on its being intrinsic to the individual and on the individual's being deduced from it. This last represents the stage in the development of thought in which the individual is produced out of the universal. What follows, therefore, is an account of the different universals expressed both in judgements and in syllogisms.

\section{The Universal as Quality}

This is an abstract universal whereby the individual is defined by the isolation of only one of its qualities. This single quality is made to account for the individual as a whole. Universality of this kind is characteristic of knowledge of the individual acquired through the senses. Contrary to what common sense would lead us to believe and philosophers generally assume, knowledge of the individual by way of the senses does not take into account qualities of the subject other than the one selected; and the quality by means of which the universal defines the subject does not belong exclusively to the particular individual being considered, but is a common quality shared by other individuals. ${ }^{15}$ 
This double abstraction, consisting in the negation of the individual by the universal on two levels, results in a very weak connection being established between subject and predicate. So, if it is observed for example that a rose is red and fire is red, fire and rose are taken to be the same thing. The same individual can thus pertain to various universals, and is therefore not really subsumed in a universal. Hence at this stage in the history of thought, no fixed classification of individuals as yet exists. Genera, insofar as they already exist, are interchangeable, so that the individual is not as yet an instance of his species.

\section{The Universal as Genus}

Another universal is that of species and genera. 16 Genera are universals that define the essence of individuals. Essence is no longer conceived of as a single quality but as a diversity of qualities. It is at this stage that substance emerges for the first time as a.genus that defines the totality of a species.

This universal is less abstract than the preceding one. Nevertheless it is abstract in the degree that the species are not deduced from the genus, which is an undesirable state of affairs in the genus-species relationship. Indeed, Hegel explicitly states that at this stage in the development of that thought, the diversity of species are dealt empirically as they are found, and are not logically deduced from the genera.17 The individual is therefore extrinsic to the universal. since the individual is not entirely deduced from the universal; generalization, induction, and analogy are required to account for it (Science 687-95; Encyclopedia sect. 190). These methods of inquiry into the individual represent sequential stages, each method being adopted in turn, when the preceding method fails in grasping the nature of the individual.

Thus in generalization we aspire to deduce the instances of the species from the genus. However this is impossible, since the individual is not intrinsic to the genus but only associated with it as a result of empirical experience. So, for example, the different species of animals are not deduced from the generic concept of animal, but are empirically discovered in nature. The universal concept of animal only points to that which the individual animal has in common with other individual animals. The universal therefore does not define an individual, but the sum of individuals. But by its very nature the individual is more than merely the qualities it shares with other individuals, and it therefore still remains independent of, and undefined by, the universal. This is a problem that is ultimately beyond the capacity of empiricism to solve.

The individual can be better grasped by means of -induction. From the point of view of induction, the 
trouble with generalization is that it does not encompass all instances, an aim to which it can only aspire as an ideal goal (Science 694-5) In generalization it is assumed that the instances are deduced from the genus, whereas induction is undertaken in regard to actually existing individuals, and thereby does away with the need for generalization. In induction all instances must be exhausted in order to arrive at a general statement. But the problem is that it can never be known if this goal has in fact been achieved; in other words, there can be no certainty concerning the actual attainment of universality. The assumption of induction is that the individual is not found in its species. To pat it another way, the presence of the individual in the universal is only an ideal possibility. It would therefore seem that induction may be conceived of as a sort of provisional deduction.

This demand for a provisional deduction is fulfilled by the method of analogy. Induction presupposes analogy, for it requires going beyond the individual case; indeed, analogy arises out of the awareness that universally valid conclusions cannot be arrived at from individual cases. The task of the analogy is therefore to widen the scope of knowledge by means of referring one species to another. ${ }^{1 *}$

\section{The Universal as Law}

Analogy represents the furthest limit to which empiricism is able to take thought, and the judgements that pertain to it can only be made within the bounds of probability. According to Hegel, empiricism can be transcended (in the sense of Aufhebung) by means of rethinking the concept of genus. Species are subsumed under genera, and it is by means of this subsumption that species are different from one another; that is to say, they are now different entities primordially and by definition. Hence the significance of genus is that it determines the difference among species. In its abstract guise, genus had formerly been indifferent to difference within itself; whereas now, in what Hegel calls the. Judgement of Necessity, the universal is defined through difference (cf. Science 650, 695; Encyclopedia sect. 178, 191).

Erom a historical point of view, this is the universal that underlies the idea of laws of nature in modern science. A law of nature is concerned with individuals insofar as they conceived of as being determined by their relations to other individuals. To deal with individuals by means of natural laws is to employ relations as universals. That is to say, individuals are wholly and necessarily deduced from the relation as such; and since the universals are concerned solely with the relation and not with the terms of relation, all that can be stated at this stage is a hypothetical 
judgement wherein the only necessity is that of the relation: "If A is, then B is;" or, in Hegel's words, "The being of $A$ is not its own being, but the being of another, of $B^{\prime \prime}$ (Science 652).

\section{The Universal as Subject}

The difficulty in the foregoing is that the connection as such cannot answer the question of whether the terms exist. It can only be stated that if they do exist, they are necessarily related to one another. Awareness of this difflculty is what accounts for the quest for a more intimate linking of the individual with the universal. This takes place in what Hegel calls the Judgment of the Concept (Science 657; Encyclopedia sect. 178). The universal now refers to a totality which includes in itself a differentiation into individuals. Such a universal is called by Hegel "concrete universality" (Science 659ff). This is a universality that creates its species, and is therefore an active universal.

What, then, are the "domains of reality" wherein it is posisible for the universal to create what is included in it? Certainly not in science. It is only in the field of human affairs that such a thing can take place. This is why Hegel also calls this form of judgement "value judgement." In the sphere of human activity man himself creates the laws in which he, as individual, is subsumed.

This is the pinnacle of speculative thought; that is to say, of the theoretical understanding of "practical reason." It can best be understood through Hegel's defense of the ontological proof of the existence of God, which deals with creation of reality out of essence. In the ontological argument, the concept proper becomes substance; in other words, the subject that himself conceives concepts becomes substance. This is moreover an "inverted" substantiality, a rational substance.

The idea of substance being rational is the hard core of the Hegelian system. If science is a systematically achieved knowledge of the world, then from the point of view of the process of thought, the world should appear as a substantiation of concepts; and conceptualization (i.e., the creation of concepts) is to be understood as the process of turning substance into subject.

Indeed, the ideal of all science is the translation of reality into reason. The historical development of science can therefore be conceived of as being twofold: as the increasing appropriation of ever larger portions of reality by reason; and as the appropriation of reason by self-consciousness. 19

Both processes are historically parallel and interactive; and in Hegel, philosophy in the sense of self- 
consciousness reaches its zenith, at least with respect to intention. This is the significance of Hegel's idea of substance becoming subject and reality becoming reason.

\section{NOTES}

I should like to express my gratitude to the anonymous reviewers of this article for their helpful comments.

'I regard Hegel's well-known statement that "what is rational is real (actual) and what is real is rational" to refer to the process of reality becoming spirit (see Philosophy of Right, preface; Encyclopedia, sect. 6). This process does not consist in a transition from one reality to another; rather, reality becomes once more what it had been but was not yet aware of being, namely Spirit. Reality is not rational when it lacks consciousness. It only becomes rational when it is self-consciousness (cf. Encyclopedia, sect. 142, 439; Phenomenology of Spirit, I.V.1). Hegel does not regard the form and content of knowledge to be independent of one another: ". . . form in its most concrete signification is reason as speculative knowing, and content is reason as the substantial essence of actuality, whether ethical or natural" (Philosophy of Right, trans. T. M. Knox [London: Oxford University $\overline{\text { Press, }}$ 1952 J, 12).

${ }^{2}$ G.W.F. Hegel, Philosophy of Right, preface.

${ }^{3}$ Cf. Gottfried W. Leibniz, New Essays, IV, 2.1.

"Hegel, The Science of Logic, trans. A. V. Miller (London: George Allen and Unwin, 1969), 575. Hereafter cited as Science.

${ }^{5}$ See Plato, Meno, 75d, 79d.

'We might ask here about how error is to be accounted for. But this question is irrelevant, since a false judgement is no less a judgement for being wrong. When I say, for example, that the square root of eight is three, despite my error, I am relating the predicate to the subject no less than when $I$ assert a true judgement.

${ }^{7}$ Common sense, on the other hand, accepts concepts as finished products, and takes no account of the process of thinking entailed by them. 
'I use the term 'meaning' to denote the intended content of judgements--that is to say, the object or issue to which the judgement refers.

'For Hegel's treatment of identity and tautology. see Science, 411-17.

$1{ }^{\circ}$ For further examples see Encyclopedia, sect. 167. It is noteworthy that Hegel, perhaps with the intention of giving his argument greater force, has included a false datum in his example (Aristotle's age at his death was 63 and not 73). In this way he may be stressing, perhaps, the irrelevance of content to this example. Hegel argues that this is not a judgement at all, but a mere sentence, and this seems to be his general opinion of examples of this type. The main point of such illustrations of judgement is the form and not the content of judgement. Indeed it is impossible to give an example of a judgement, for no sooner is a judgement treated as an example than it ceases being a judgement and becomes a sentence. In this particular example. the date of Aristotle's death is of no significance, for the reason that it is only an example and has no specific context of its own in which it could be significant. Even the universal framework of time is meaningless because most readers are ignorant of the significance of any particular olympic year. It seems to me to have been no accident that Hegel did not add, even parenthetically, the date according to the Gregorian calendar, as is the rule in Lessons in the History of Philosophy. Hegel thereby emphasizes even more strongly the insignificance of Aristotle's age and the date at the time of his death for the reader, who more than likely will not trouble to check the data of what is after all no more than an illustrative example.

${ }^{11} \mathrm{Had}$ he wanted to do so, Hegel could have given his friend's name in full, rather than just the initial ' $N$ '. In any case, this is no way to refer to a friend. However, had the death of Hegel's friend been relevant, the statement would have been a judgement.

${ }^{12}$ It should be observed that Hegel's approach to judgement and sentences presupposes that no distinction can be made between syntax and semantics. Where there is no meaning, not even syntax exists, but only a group of sounds governed by no rules.

"Individuality is defined negatively--i.e., as the negation of universality within the universal. "What this means is that the individual is defined by the universal as being different. See Science, 621.

"Judgement is this mediation of the universal by the particular and the individual. See Science, 601-2. 
${ }^{13} \mathrm{Cf}$. Phenomenology, 93-5. This is the judgement of existence (Science, 630-643), called "qualitative judgement" in the Encyclopedia (sect. 172).

ichegel calls this kind of universal the "Judgement of Reflection" (Science, 643).

1'See Science, 646, 648. When Hegel says "empirical" he means "the concept of the empirical," when he says "nature" he means "the concept of nature," and so on. For Hegel, empiricism is a concept. Ultimately, everything resides in Spirit:

"What Hegel calls the Judgment of Reflection may be conceived of historically as the classical or Aristotelian way of thinking--that is, thinking by means of species and genera as universals. This mode of thinking is called by Ernest Cassirer "substantial thought"; see Ernest Cassirer, Substance and Eunction (Chicago: Open Court Pub., 1923), ch. 1 .

'Of course these are not Hegel's own formulations, since for him there exists nothing extrinsic to spirit. Nevertheless, it appears to me that by deflating Hegel's original formulations, his philosophy can be more easily approached and better understood. 